Published in final edited form as:

J Neurogenet. 2020 ; 34(3-4): 475-481. doi:10.1080/01677063.2020.1839066.

\title{
Neuromodulators: an essential part of survival
}

\author{
Joy Alcedo ${ }^{a}$, Veena Prahlad ${ }^{b}$ \\ aDepartment of Biological Sciences, Wayne State University, Detroit, MI, USA; \\ bDepartment of Biology, Aging Mind and Brain Initiative, and lowa Neuroscience Institute, \\ University of lowa, lowa City, IA, USA
}

\begin{abstract}
The coordination between the animal's external environment and internal state requires constant modulation by chemicals known as neuromodulators. Neuromodulators, such as biogenic amines, neuropeptides and cytokines, promote organismal homeostasis. Over the past several decades, Caenorhabditis elegans has grown into a powerful model organism that allows the elucidation of the mechanisms of action of neuromodulators that are conserved across species. In this perspective, we highlight a collection of articles in this issue that describe how neuromodulators optimize $C$. elegans survival.
\end{abstract}

\section{Keywords}

Octopamine; tyramine; dopamine; serotonin; FMRFamide-like peptides; insulin-like peptides; non-FLP; non-ILP neuropeptides; $C$. elegans; neuromodulators; survival; homeostasis

An animal receives multiple environmental stimuli, some of which have the potential to disrupt metabolism and overall physiology. To survive environmental stressors, an animal must transition between a range of internal states and behaviors to identify new set points at which its physiological processes function optimally, thereby regaining homeostasis. One mechanism by which all organisms, including Caenorhabditis elegans, integrate changes in their external environments with their internal states is through the secretion of chemicals known as neuromodulators, which allow the animal to best exploit its niche and prioritize survival. This perspective introduces a series of articles in this collection that highlight the role of these chemicals in survival programs, aging and disease.

\section{What are neuromodulators?}

Neuromodulators were discovered as brain chemicals that transform a neuron's intrinsic excitability or synaptic dynamics (see Bargmann, 2012; Bargmann \& Marder, 2013; Marder, 2012; Taghert \& Nitabach, 2012, for excellent reviews on neuromodulator function). In contrast to classical neurotransmitters, diverse members of this class of chemicals, such as

CONTACT Joy Alcedo joy.alcedo@wayne.edu Department of Biological Sciences, Wayne State University, Detroit, MI, USA; Veena Prahlad veena-prahlad@uiowa.edu Department of Biology, University of Iowa, Iowa City, IA, USA.

Disclosure statement

No potential conflict of interest was reported by the author(s). 
monoamines, neuropeptides, and cytokines, can be released extrasynaptically from neural sources (Bargmann, 2012; Bargmann \& Marder, 2013; Bentley et al., 2016; Marder, 2012; Taghert \& Nitabach, 2012). They can also be released from non-neural sources (Marder, 2012; Taghert \& Nitabach, 2012). Neuromodulators act locally in a paracrine manner or act hormonally at neural or non-neural targets far from their site of release (Bargmann, 2012; Bargmann \& Marder, 2013; Hobert, 2013; Marder, 2012; Schafer, 2006; Taghert \& Nitabach, 2012). They can modify the outputs of anatomically defined neural circuits or alter the composition of these circuits to generate entirely different outputs (Bargmann, 2012; Bargmann \& Marder, 2013; Marder, 2012; Taghert \& Nitabach, 2012). To add to their complexity, a neuromodulator may promote one response by enhancing one cell's activity and/or repressing the activity of another (Bargmann \& Marder, 2013; Marder, 2012). Then, due to a change in local cell environments, that same neuromodulator may promote a second or opposite response by affecting the activities of other cells that now express the appropriate receptors (Bargmann \& Marder, 2013; Di Giovangiulio et al., 2015; Marder, 2012; Schafer, 2006). This multiplicity of effects by neuromodulators has made their study particularly challenging.

\section{Neuromodulators in C. elegans survival}

Thanks to the pioneering work of Brenner, Sulston, and others, the worm $C$. elegans has grown into a powerful experimental system to study the effects of neuromodulators on all aspects of animal physiology. Caenorhabditis elegans expresses all the major classes of neuromodulators, which include the biogenic amines (serotonin, dopamine, octopamine, and tyramine; Bentley et al., 2016), neuropeptides (short peptides that are processed posttranslationally from precursor proteins; reviewed by Hobert, 2013; Li \& Kim, 2008), and cytokines [such as TGF- $\beta$ and the interleukin IL-17 (Bargmann, 2012; Chen et al., 2017)]. The worm's extra-ordinary tractability to forward and reverse genetics allows the easy manipulation of neuromodulators and their receptors in specific cells and visualization of the subsequent changes in cellular properties, behavior, and physiology. The secretion of neuromodulators by neural or non-neural tissues into the worm pseudocoelomic cavity also facilitates the study of the systemic effects of these chemicals-how they mediate communication between neural and non-neural cells. The above advantages of $C$. elegans has yielded a wealth of information that allows us to understand the impact of neuromodulators on its biology. Indeed, the worm's food choices, its decision to forage, mate, or reproduce, its metabolism or responses to threats and competition, its developmental programs and longevity are but some processes influenced by neuromodulators and amenable to experimental manipulation (Aprison \& Ruvinsky, 2019; Banerjee, Bhattacharya, Gorczyca, Collins, \& Francis, 2017; Beets, Temmerman, Janssen, \& Schoofs, 2013; Bhattacharya \& Francis, 2015; Cermak et al., 2020; Ezcurra, Walker, Beets, Swoboda, \& Schafer, 2016; Ghosh et al., 2016; Ishita, Chihara, \& Okumura, 2020; KagawaNagamura, Gengyo-Ando, Ohkura, \& Nakai, 2018; Ringstad, 2017; Schafer, 2006; Wu et al., 2019; Zang, Ho, \& Ringstad, 2017). 


\section{A common thread throughout this issue}

The profound influence of neuromodulators on behavior, metabolism, and overall physiology is a common thread throughout this issue (Cheon, Hwang, \& Kim, 2020; Honer et al., 2020; Kim \& Flavell, 2020; Kim, Lee, Kim, \& Lee, 2020; Liang, McKinnon, \& Rankin, 2020; Liu \& Zhang, 2020; Muirhead \& Srinivasan, 2020; Prahlad, 2020; Srinivasan, 2020; Takeishi, Takagaki, \& Kuhara, 2020; Yang, Lee, Yim, \& Lee, 2020). In this perspective, we will focus on the roles of monoamines and neuropeptides in C. elegans survival.

Monoamine modulators-Caenorhabditis elegans synthesizes four monoamine neuromodulators - octopamine (OA), tyramine (TA), dopamine (DA), and serotonin (5-HT) -but lack histamine, epinephrine, and norepinephrine, which are found in vertebrates (Bentley et al., 2016; Chase \& Koelle, 2007). The major source, and, in some cases, the only source, of these monoamine modulators are neurons. Caenorhabditis elegans mutants that lack key biosynthetic enzymes for each of the bioamine neuromodulators are viable, allowing $C$. elegans to serve as a powerful discovery platform to understand neuromodulator function. These bioactive monoamine synthesis mutants exert pleiotropic effects on $C$. elegans internal states, thereby affecting behavior (see, e.g., Cermak et al., 2020; Ghosh et al., 2016; Schafer, 2006).

Octopamine and tyramine.: $\mathrm{OA}$ and TA are considered the functional equivalent of epinephrine and norepinephrine in invertebrates (Li et al., 2017). OA and TA are best characterized in orchestrating the transition between the foraging state, which is elicited by lack of food, and the dwelling state, which denotes food availability. TA is present in low abundance and is synthesized by the enzyme tyrosine decarboxylase (TDC-1) in the RIM-1 motor neurons, gonadal sheath cells, and the uv1 neuroendocrine cells (Alkema, HunterEnsor, Ringstad, \& Horvitz, 2005; Chase \& Koelle, 2007). OA is synthesized from TA by the enzyme tyramine $\beta$-hydroxylase (TBH-1) in RIC interneurons and the gonadal sheath cells (Alkema et al., 2005; Chase \& Koelle, 2007; Horvitz, Chalfie, Trent, Sulston, \& Evans, 1982). Food deprivation results in the release of OA by the RIC neurons (Churgin, McCloskey, Peters, \& Fang-Yen, 2017; Roeder, 2020; Suo, Culotti, \& Van Tol, 2009). The released OA acts via the G protein-coupled receptors (GPCRs) SER-3 and SER-6 in SIA neurons to promote roaming behaviors that increase the probability of finding food (Churgin et al., 2017; Suo et al., 2009). When food becomes available, TA promotes reduced locomotion to allow feeding (Churgin et al., 2017).

Caenorhabditis elegans is a bacterivore, and the bacteria encountered by the animal range from highly nutritious to poorly nutritious and outright pathogenic (see Kim \& Flavell, 2020; this issue). Interestingly, OA also suppresses aversive behaviors (Guo et al., 2015; Mills et al., 2012) to prioritize feeding. OA allows $C$. elegans to tolerate low-quality or detrimental bacterial food sources by modulating bacteria-elicited innate immune responses (Sellegounder, Yuan, Wibisono, Liu, \& Sun, 2018; Suo et al., 2009). Consequently, OA mediates a shift towards attraction to a greater range of foods, like altering the valence of the response to $\mathrm{CO}_{2}$ levels that typically signify food (Rengarajan, Yankura, Guillermin, Fung, $\&$ Hallem, 2019). In this issue, Srinivasan (2020) discusses how RIC neuron-secreted OA 
coordinates food availability with lipolytic activity by signaling through intestinal SER-3 receptors to activate the intestinal lipases LIPS-6 and ATGL-1.

Remarkably, C. elegans is subject to signaling not only from its self-synthesized OA, but also from OA or OA-like compounds secreted by certain bacteria or other C. elegans, respectively. In this issue, Kim and Flavell (2020) highlight the recent findings from the Sengupta lab (O'Donnell, Fox, Chao, Schroeder, \& Sengupta, 2020) on how OA produced by commensal bacteria alters $C$. elegans behavior and internal state. Cheon et al. (2020; this issue) and Muirhead and Srinivasan (2020; this issue) also review how starved larvae produce the OA-like small molecule osas\#9, an ascaroside component of the worm-secreted pheromone blend, which is then sensed by nociceptive ASH neurons in adults to initiate their avoidance behavior (Chute et al., 2019).

Dopamine.: The DA neurons in C. elegans were initially identified by Sulston and coworkers (Sulston, Dew, \& Brenner, 1975), using the catecholamine-specific technique of formaldehyde-induced fluorescence (FIF). DA is synthesized in eight neurons (ADEL/R, $\mathrm{CEPDL} / \mathrm{R}, \mathrm{CEPVL} / \mathrm{R}$, and PDEL/R) in hermaphrodites and in six additional neurons (R5AL/R, R7AL/R, R9AL/R) in males by the tyrosine hydroxylase CAT-2, which catalyzes the rate-limiting step in dopamine synthesis (Lints \& Emmons, 1999; Sulston, Dew, \& Brenner, 1975). As in other animals, $C$. elegans DA plays key roles in coordinating motor programs with the reward system during foraging, feeding, and egg laying (Ardiel et al., 2016; Bettinger \& McIntire, 2004; Chase \& Koelle, 2007; Cermak et al., 2020; Qin \& Wheeler, 2007; Rivard et al., 2010; Sanyal et al., 2004; Sawin, Ranganathan, \& Horvitz, 2000; Suo et al., 2019). DA is released upon sensing food (Oranth et al., 2018) to initiate the slowing of movement in the presence of food (Sawin et al., 2000). Thus, DA counteracts OA-induced hyperactivity (Luedtke, O'Connor, Holden-Dye, \& Walker, 2010; Rengarajan, Yankura, Guillermin, Fung, \& Hallem, 2019). Similarly, DA works antagonistically to OA in switching the responses to $\mathrm{CO}_{2}$ : DA promotes aversion to $\mathrm{CO}_{2}$ in the fed state and $\mathrm{OA}$ promotes attraction in the starved state (Rengarajan et al., 2019). As in mammalian neurodegenerative models, $C$. elegans DA neurons appear more susceptible to degeneration upon expression of disease-associated aggregation-prone proteins, such as a-synuclein (Mor et al., 2017). In this collection, the Rankin lab focuses on how $C$. elegans serves as a powerful model in which to study neurodegeneration (Liang, McKinnon, \& Rankin, 2020).

Serotonin.: The rate-limiting enzyme tryptophan hydroxylase, TPH-1, synthesizes 5-HT in eight to ten neurons in hermaphrodites (ADFL/R, NSML/R, HSNL/R, ASGL/R upon hypoxia, and rarely in AIM and RIH) and in more neurons in males (CP0 to CP06 and the B-type ray neurons R1BL/R, R3BL/R, and R9BL/R; Hare \& Loer, 2004; Loer \& Kenyon, 1993; Loer \& Rivard, 2007; Pocock \& Hobert, 2010; Serrano-Saiz et al., 2017). Release of 5-HT from each of these neurons performs different functions, either because of its corelease with other neurotransmitters (Srinivasan, 2020; this issue) or because the acute versus chronic availability of 5-HT exerts different effects on target tissues (Prahlad, 2020; this issue). In the worm, 5-HT can mimic food and favorable conditions or signal stress, based upon the duration and site of release (Avery \& You, 2012; Chase \& Koelle, 2007; Cruz-Corchado, Ooi, Das, \& Prahlad, 2020; Curran \& Chalasani, 2012; Ishita, Chihara, \& 
Okumura, 2020; Rankin, 2006). For instance, 5-HT can promote recovery from the developmental arrest known as dauer that forms in response to early life stress (Cassada \& Russell, 1975; Mylenko et al., 2016; see also Yang, Lee et al., 2020), by mimicking food signals that promote growth and differentiation (Srinivasan, 2020; this issue). Alternatively, 5-HT can activate behavioral avoidance responses or stress-responsive transcription programs (Prahlad, 2020; this issue). Notably, these opposing effects resemble what is observed during the administration of 5-HT modulators for the treatment of neuropsychiatric disorders in humans: an acute increase in 5-HT availability causes increased anxiety; chronic treatment leads to anti-depressant effects (Sharp \& Cowen, 2011).

Neuropeptides-The $C$. elegans genome contains more than 120 genes that encode neuropeptide precursor proteins, and these proteins are processed to more than 250 neuropeptides. Most of their receptors belong to the large GPCR family but can also include ion channels and receptor kinases (for more extensive reviews on neuropeptides and their receptors, see Hobert, 2013; Li \& Kim, 2008). Caenorhabditis elegans has the FMRFamidelike peptides (FLPs; Li, Kim, \& Nelson, 1999), insulin-like peptides (ILPs; Pierce et al., 2001), and the non-FLP, non-ILP neuropeptides called NLPs (Nathoo, Moeller, Westlund, \& Hart, 2001). Like the biogenic amines, neuropeptides have also been extensively studied in C. elegans and are implicated in behaviors and physiological mechanisms that modulate homeostasis and survival.

FMRFamide-like peptides.: A prominent example of a worm FLP-dependent pathway is neuropeptide Y signaling, which is represented by the FLP-21 peptide ligand and its associated GPCR, NPR-1 (Rogers et al., 2003). FLP-21 and NPR-1 are required for avoidance responses to noxious stimuli and loss of pathway activity compromises survival (Glauser et al., 2011; Reddy, Andersen, Kruglyak, \& Kim, 2009; Styer et al., 2008). In this issue, Kim and Flavell (2020) review how this pathway can alter $C$. elegans behavior in response to bacterial metabolites in the animal's natural environment. Other FLP genes also modulate longevity and metabolism. In this collection, Kim et al. (2020) describe the role of flp-6 in increasing survival at high temperatures, but flp- 6 also intriguingly exhibits an opposite role in survival at lower temperatures (Chen et al., 2016). Srinivasan (2020; this issue) discusses how FLP-17 coordinates environmental oxygen levels with intestinal fat metabolism. Yang et al. (2020; this issue) refer to findings by the Sternberg lab (Lee et al., 2017), where peptides encoded by two flp genes, $f l p-10$ and $f l p-17$, facilitate a dispersal behavior adopted by dauers in migrating to environments that support better survival.

Insulin-like peptides.: ILP signaling has long been associated with survival (see Kenyon, 2010; and references therein). The worm ILP receptor DAF-2, which is a receptor tyrosine kinase (Kimura, Tissenbaum, Liu, \& Ruvkun, 1997), promotes reproductive growth and inhibits dauer arrest (Riddle, Swanson, \& Albert, 1981). The downregulation of DAF-2 activity doubles $C$. elegans lifespan (Kenyon, Chang, Gensch, Rudner, \& Tabtiang, 1993), a discovery that ushered the birth of a field - the genetics of aging. Like DAF-2 (Gems et al., 1998), at least some of the worm ILPs (Hobert, 2013; Li \& Kim, 2008) have pleiotropic functions (Fernandes de Abreu et al., 2014), which might be a consequence of their ILP-toILP network organization, where one ILP regulates multiple ILPs (Fernandes de Abreu et 
al., 2014). Many of the ILP functions typify neuromodulator functions. For example, there are ILPs that sometimes behave like the DAF-2 receptor in one context and opposite from DAF-2 in another context (Fernandes de Abreu et al., 2014). The articles in this collection discuss the roles of ILPs in temperature-sensing (see Takeishi, Takagaki, \& Kuhara, 2020), in context-dependent avoidance behaviors (see Cheon, Hwang, \& Kim, 2020; Kim \& Flavell, 2020), in neuroprotection (see Liang, McKinnon, \& Rankin, 2020), the dauer program (see Yang et al., 2020), and longevity (see Kim et al., 2020).

Non-FLP, non-ILP neuropeptides.: NLPs comprise a heterogeneous group of neuropeptides, but are again involved in diverse physiological processes (Li \& Kim, 2008; Hobert, 2013), from sleep behaviors (see Honer, Buscemi et al., 2020; this issue) to neurodegeneration (Lezi et al., 2018) and longevity (Park, Link, \& Johnson, 2010). Similar to FLPs and ILPs, NLPs can amplify or dampen signaling at specific synapses (Chalasani et al., 2010; Hapiak et al., 2013; Macosko et al., 2009), thereby shaping circuit connectivities and behaviors. The three classes of neuropeptides, the FLPs, ILPs, and NLPs, are also known to work together through feedforward or feedback mechanisms to maintain homeostasis at both the circuit level and the organismal level (Chalasani et al., 2010; Chen, Chen et al., 2016).

\section{Coda}

The dysregulation of neuromodulator activities can lead to disease. Indeed, numerous studies in mammalian systems implicate neuromodulator dysfunction in neurodegenerative diseases, such as Alzheimer's disease, Huntington's disease and Parkinson's disease, where impaired neuromodulator signaling often preempt disease symptoms (Du, Pang, \& Hannan, 2013; Elsworthy \& Aldred, 2019; Ohno, Shimizu, Tokudome, Kunisawa, \& Sasa, 2015; Politis \& Niccolini, 2015). Caenorhabditis elegans expresses many orthologs of neurodegenerative disease-associated genes and their study in the worm have contributed to our understanding of the above human diseases (see Liang, McKinnon, \& Rankin, 2020; this issue). Understanding the role of neuromodulators in worm neurodegeneration will likely add to our understanding of human neurodegenerative disorders.

To conclude, we would like to highlight an important question. How does a neuromodulator modify a physiological response to a stimulus? This question circles back to experiments performed in the 1960s. Injection of an abdominal ganglion extract from one Aplysia into another Aplysia elicited the cessation of locomotor and feeding behavior, followed by the stereotyped head-waving behavior that facilitated egg laying in the second animal (Kupfermann, 1967; Strumwasser, Jacklet, \& Alvarez, 1969; Toevs \& Brackenbury, 1969). These experiments demonstrated that diverse modulatory substances could act centrally and peripherally to change the physiological state of an animal completely. It would be interesting to learn the rules and constraints by which different cocktails of neuromodulators achieve such a dramatic switch in physiological responses to environmental stimuli. Ultimately, the complete identification of the interacting modulators, their receptors and sites of action should allow us to address this question. We posit that $C$. elegans is an ideal system to achieve this goal. 


\section{Acknowledgments}

The authors apologize to the authors whose work we were unable to cite due to space constraints and the daunting scale of the C. elegans literature in neuromodulation. The authors would also like to thank the two reviewers for their valuable critiques of this perspective.

Funding

This work was supported by NIH [R01 GM108962] to J. A. and [R01 AG060616 and R01 AG050653] to V. P.

\section{References}

Alkema MJ, Hunter-Ensor M, Ringstad N, \& Horvitz HR (2005). Tyramine functions independently of octopamine in the Caenorhabditis elegans nervous system. Neuron, 46(2), 247-260. doi:10.1016/ j.neuron.2005.02.024 [PubMed: 15848803]

Aprison EZ, \& Ruvinsky I (2019). Dynamic regulation of adult-specific functions of the nervous system by signaling from the reproductive system. Current Biology : CB, 29(23), 4116-4123.e4113. doi:10.1016/j.cub.2019.10.011 [PubMed: 31708396]

Ardiel EL, Giles AC, Yu AJ, Lindsay TH, Lockery SR, \& Rankin CH (2016). Dopamine receptor DOP-4 modulates habituation to repetitive photoactivation of a C. elegans polymodal nociceptor. Learning \& Memory (Cold Spring Harbor, N.Y.), 23(10), 495-503. doi:10.1101/1m.041830.116

Avery L and You YJ C. elegans feeding, WormBook, ed. The C. elegans Research Community, WormBook, doi/10.1895/wormbook.1.150.1

Banerjee N, Bhattacharya R, Gorczyca M, Collins KM, \& Francis MM (2017). Local neuropeptide signaling modulates serotonergic transmission to shape the temporal organization of C. elegans egglaying behavior. PLoS Genetics, 13(4), e1006697. doi:10.1371/journal.pgen.1006697 [PubMed: 28384151]

Bargmann CI (2012). Beyond the connectome: How neuromodulators shape neural circuits. BioEssays: News and Reviews in Molecular, Cellular and Developmental Biology, 34(6), 458-465. doi:10.1002/bies.201100185

Bargmann CI, \& Marder E (2013). From the connectome to brain function. Nature Methods, 10(6), 483-490. doi:10.1038/nmeth.2451 [PubMed: 23866325]

Beets I, Temmerman L, Janssen T, \& Schoofs L (2013). Ancient neuromodulation by vasopressin/ oxytocin-related peptides. Worm, 2(2), e24246. doi:10.4161/worm.24246 [PubMed: 24058873]

Bentley B, Branicky R, Barnes CL, Chew YL, Yemini E, Bullmore ET, ... Schafer WR (2016). The multilayer connectome of Caenorhabditis elegans. PLoS Computational Biology, 12(12), e1005283. doi:10.1371/journal.pcbi.1005283 [PubMed: 27984591]

Bettinger JC, \& McIntire SL (2004). State-dependency in C. elegans. Genes Brain, and Behavior, 3(5), 266-272. doi:10.1111/j.1601-183X.2004.00080.x

Bhattacharya R, \& Francis MM (2015). In the proper context: Neuropeptide regulation of behavioral transitions during food searching. Worm, 4(3), e1062971. doi:10.1080/21624054.2015.1062971 [PubMed: 26430569]

Cassada RC, \& Russell RL (1975). The dauerlarva, a post-embryonic developmental variant of the nematode Caenorhabditis elegans. Developmental Biology, 46(2), 326-342. doi:10.1016/0012-1606(75)90109-8 [PubMed: 1183723]

Cermak N, Yu SK, Clark R, Huang YC, Baskoylu SN, \& Flavell SW (2020). Whole-organism behavioral profiling reveals a role for dopamine in state-dependent motor program coupling in $C$. elegans. eLife, 9, e57093. doi:10.7554/eLife.57093 [PubMed: 32510332]

Chalasani SH, Kato S, Albrecht DR, Nakagawa T, Abbott LF, \& Bargmann CI (2010). Neuropeptide feedback modifies odor-evoked dynamics in Caenorhabditis elegans olfactory neurons. Nature Neuroscience, 13(5), 615-621. doi:10.1038/nn.2526 [PubMed: 20364145]

Chase DL, \& Koelle MR (2007). Biogenic amine neurotransmitters in C. elegans. WormBook, 1-15. doi:10.1895/wormbook.1.132.1 
Chen C, Itakura E, Nelson GM, Sheng M, Laurent P, Fenk LA, ... de Bono M (2017). IL-17 is a neuromodulator of Caenorhabditis elegans sensory responses. Nature, 542(7639), 43-48. doi:10.1038/nature20818 [PubMed: 28099418]

Chen YC, Chen HJ, Tseng WC, Hsu JM, Huang TT, Chen CH, \& Pan CL (2016). A C. elegans thermosensory circuit regulates longevity through crh-1/CREB-dependent flp-6 neuropeptide signaling. Developmental Cell, 39(2), 209-223. doi:10.1016/j.devcel.2016.08.021 [PubMed: 27720609]

Cheon Y-J, Hwang H, \& Kim K (2020). Plasticity of pheromone-mediated avoidance behavior in $C$. elegans. Journal of Neurogenetics, 34.doi: 10.1080/01677063.2020.1802723

Churgin MA, McCloskey RJ, Peters E, \& Fang-Yen C (2017). Antagonistic serotonergic and octopaminergic neural circuits mediate food-dependent locomotory behavior in Caenorhabditis elegans. Journal of Neuroscience: The Official Journal of the Society for Neuroscience, 37(33), 7811-7823. doi:10.1523/JNEUROSCI.2636-16.2017

Chute CD, DiLoreto EM, Zhang YK, Reilly DK, Rayes D, Coyle VL, ... Srinivasan J (2019). Cooption of neurotransmitter signaling for inter-organismal communication in $C$. elegans. Nature Communications, 10(1), 3186. doi:10.1038/s41467-019-11240-7

Cruz-Corchado J, Ooi FK, Das S, \& Prahlad V (2020). Global transcriptome changes that accompany alterations in serotonin levels in Caenorhabditis elegans. G3 (Bethesda, Md.), 10(4), 1225-1246. doi: $10.1534 / \mathrm{g} 3.120 .401088$

Curran KP, \& Chalasani SH (2012). Serotonin circuits and anxiety: What can invertebrates teach us? Invertebrate Neuroscience, 12(2), 81-92. doi:10.1007/s10158-012-0140-y [PubMed: 22918570]

Di Giovangiulio M, Verheijden S, Bosmans G, Stakenborg N, Boeckxstaens GE, \& Matteoli G (2015). The neuromodulation of the intestinal immune system and its relevance in inflammatory bowel disease. Frontiers in Immunology, 6, 590. doi:10.3389/fimmu.2015.00590 [PubMed: 26635804]

Du X, Pang T, \& Hannan A (2013). A tale of two maladies? Pathogenesis of depression with and without the Huntington's disease gene mutation. Frontiers in Neurology, 4, 81. doi:10.3389/ fneur.2013.00081 [PubMed: 23847583]

Elsworthy RJ, \& Aldred S (2019). Depression in Alzheimer's disease: An alternative role for selective serotonin reuptake inhibitors? Journal of Alzheimer's Disease, 69(3), 651-661. doi:10.3233/ JAD-180780

Ezcurra M, Walker DS, Beets I, Swoboda P, \& Schafer WR (2016). Neuropeptidergic signaling and active feeding state inhibit nociception in Caenorhabditis elegans. Journal of Neuroscience: The Official Journal of the Society for Neuroscience, 36(11), 3157-3169. doi:10.1523/ JNEUROSCI.1128-15.2016

Fernandes de Abreu DA, Caballero A, Fardel P, Stroustrup N, Chen Z, Lee K, ... Ch'ng Q (2014). An insulin-to-insulin regulatory network orchestrates phenotypic specificity in development and physiology. PLoS Genetics, 10(3), e1004225. doi:10.1371/journal.pgen.1004225 [PubMed: 24675767]

Gems D, Sutton AJ, Sundermeyer ML, Albert PS, King KV, Edgley ML, ... Riddle DL (1998). Two pleiotropic classes of daf-2 mutation affect larval arrest, adult behavior, reproduction and longevity in Caenorhabditis elegans. Genetics, 150(1), 129-155. [PubMed: 9725835]

Ghosh DD, Sanders T, Hong S, McCurdy LY, Chase DL, Cohen N, ... Nitabach MN (2016). Neural architecture of hunger-dependent multisensory decision making in C. elegans. Neuron, 92(5), 1049-1062. doi:10.1016/j.neuron.2016.10.030 [PubMed: 27866800]

Glauser DA, Chen WC, Agin R, Macinnis BL, Hellman AB, Garrity PA, Goodman MB (2011). Heat avoidance is regulated by transient receptor potential (TRP) channels and a neuropeptide signaling pathway in Caenorhabditis elegans. Genetics, 188(1), 91-103. doi:10.1534/genetics.111.127100 [PubMed: 21368276]

Guo M, Wu T-H, Song Y-X, Ge M-H, Su C-M, Niu W-P, ... Wu Z-X (2015). Reciprocal inhibition between sensory ASH and ASI neurons modulates nociception and avoidance in Caenorhabditis elegans. Nature Communications, 6, 5655. doi:10.1038/ncomms6655

Hapiak V, Summers P, Ortega A, Law WJ, Stein A, \& Komuniecki R (2013). Neuropeptides amplify and focus the monoaminergic inhibition of nociception in Caenorhabditis elegans. Journal of 
Neuroscience, 33(35), 14107-14116. doi:10.1523/JNEUROSCI.1324-13.2013 [PubMed: 23986246]

Hare EE, \& Loer CM (2004). Function and evolution of the serotonin-synthetic bas-1 gene and other aromatic amino acid decarboxylase genes in Caenorhabditis. BMC Evolutionary Biology, 4, 24. doi:10.1186/1471-2148-4-24 [PubMed: 15287963]

Hobert O (2013). The neuronal genome of Caenorhabditis elegans. WormBook, 1-106. doi:10.1895/ wormbook.1.161.1

Honer M, Buscemi K, Barrett N, Riazati N, Orlando G, \& Nelson MD (2020). Orcokinin neuropeptides regulate sleep in Caenorhabditis elegans. Journal of Neurogenetics, 34.doi: 10.1080/01677063.2020.1830084

Horvitz HR, Chalfie M, Trent C, Sulston JE, \& Evans PD (1982). Serotonin and octopamine in the nematode Caenorhabditis elegans. Science (New York, N.Y.), 216(4549), 1012-1014. doi:10.1126/ science. 6805073

Ishita Y, Chihara T, \& Okumura M (2020). Serotonergic modulation of feeding behavior in Caenorhabditis elegans and other related nematodes. Neuroscience Research, 154, 9-19. doi:10.1016/j.neures.2019.04.006 [PubMed: 31028772]

Kagawa-Nagamura Y, Gengyo-Ando K, Ohkura M, \& Nakai J (2018). Role of tyramine in calcium dynamics of GABAergic neurons and escape behavior in Caenorhabditis elegans. Zoological Letters, 4, 19. doi:10.1186/s40851-018-0103-1 [PubMed: 30065850]

Kenyon C, Chang J, Gensch E, Rudner A, \& Tabtiang R (1993). A C. elegans mutant that lives twice as long as wild type. Nature, 366(6454), 461-464. doi:10.1038/366461a0 [PubMed: 8247153]

Kenyon CJ (2010). The genetics of ageing. Nature, 464(7288), 504-512. doi:10.1038/nature08980 [PubMed: 20336132]

Kim B, Lee J, Kim Y, \& Lee S-JV (2020). Regulatory systems that mediate the effects of temperature on the lifespan of Caenorhabdities elegans. Journal of Neurogenetics, 34. doi: 10.1080/01677063.2020.1781849

Kim DH, \& Flavell SW (2020). Host-microbe interactions and the behavior of Caenorhabditis elegans. Journal of Neurogenetics, 34.doi:10.1080/01677063.2020.1802724

Kimura KD, Tissenbaum HA, Liu Y, \& Ruvkun G (1997). daf-2, an insulin receptor-like gene that regulates longevity and diapause in Caenorhabditis elegans. Science (New York, N.Y.), 277(5328), 942-946. doi:10.1126/science.277.5328.942

Kupfermann I (1967). Stimulation of egg laying: Possible neuroendocrine function of bag cells of abdominal ganglion of Aplysia californica. Nature, 216(5117), 814-815. doi:10.1038/216814a0 [PubMed: 5624338]

Lee JS, Shih PY, Schaedel ON, Quintero-Cadena P, Rogers AK, \& Sternberg PW (2017). FMRFamide-like peptides expand the behavioral repertoire of a densely connected nervous system. Proceedings of the National Academy of Sciences of the United States of America, 114(50), E10726-E10735. doi:10.1073/pnas.1710374114 [PubMed: 29167374]

Lezi E, Zhou T, Koh S, Chuang M, Sharma R, Pujol N, ... Yan D (2018). An antimicrobial peptide and its neuronal receptor regulate dendrite degeneration in aging and infection. Neuron, 97(1), 125138.e125. doi:10.1016/j.neuron.2017.12.001 [PubMed: 29301098]

Li C, \& Kim K (2008). Neuropeptides. WormBook, 1-36. doi:10.1895/wormbook.1.142.1

Li C, Kim K, \& Nelson LS (1999). FMRFamide-related neuropeptide gene family in Caenorhabditis elegans. Brain Research, 848(1-2), 26-34. doi:10.1016/S0006-8993(99)01972-1 [PubMed: 10612695]

Li Y, Tiedemann L, von Frieling J, Nolte S, El-Kholy S, Stephano F, ... Roeder T (2017). The role of monoaminergic neurotransmission for metabolic control in the fruit fly Drosophila melanogaster. Frontiers in Systems Neuroscience, 11, 60. doi:10.3389/fnsys.2017.00060 [PubMed: 28878633]

Liang JJH, McKinnon IA, \& Rankin CH (2020). The contribution of $C$. elegans neurogenetics to understanding neurodegenerative diseases. Journal of Neurogenetics, 34.doi: 10.1080/01677063.2020.1803302

Lints R, \& Emmons SW (1999). Patterning of dopaminergic neurotransmitter identity among Caenorhabditis elegans ray sensory neurons by a TGFb family signaling pathway and a Hox gene. Development, 126(24), 5819-5831. [PubMed: 10572056] 
Liu H, \& Zhang Y (2020). What can a worm learn in a bacteria-rich habitat? Journal of Neurogenetics, 34. doi: 10.1080/01677063.2020.1829614

Loer CM, \& Kenyon CJ (1993). Serotonin-deficient mutants and male mating behavior in the nematode Caenorhabditis elegans. The Journal of Neuroscience : The Official Journal of the Society for Neuroscience, 13(12), 5407-5417. doi:10.1523/JNEUROSCI.13-12-05407.1993 [PubMed: 8254383]

Loer CM, \& Rivard L (2007). Evolution of neuronal patterning in free-living rhabditid nematodes I: Sex-specific serotonin-containing neurons. Journal of Comparative Neurology, 502(5), 736-767. doi:10.1002/cne. 21288

Luedtke S, O'Connor V, Holden-Dye L, \& Walker RJ (2010). The regulation of feeding and metabolism in response to food deprivation in Caenorhabditis elegans. Invertebrate Neuroscience, 10(2), 63-76. doi:10.1007/s 10158-010-0112-z [PubMed: 21120572]

Macosko EZ, Pokala N, Feinberg EH, Chalasani SH, Butcher RA, Clardy J, \& Bargmann CI (2009). A hub-and-spoke circuit drives pheromone attraction and social behaviour in $C$. elegans. Nature, 458(7242), 1171-1175. doi:10.1038/nature07886 [PubMed: 19349961]

Marder E (2012). Neuromodulation of neuronal circuits: Back to the future. Neuron, 76(1), 1-11. doi:10.1016/j.neuron.2012.09.010 [PubMed: 23040802]

Mills H, Wragg R, Hapiak V, Castelletto M, Zahratka J, Harris G, ... Komuniecki R (2012). Monoamines and neuropeptides interact to inhibit aversive behaviour in Caenorhabditis elegans. EMBO Journal, 31(3), 667-678. doi:10.1038/emboj.2011.422

Mor DE, Tsika E, Mazzulli JR, Gould NS, Kim H, Daniels MJ, ... Ischiropoulos H (2017). Dopamine induces soluble a-synuclein oligomers and nigrostriatal degeneration. Nature Neuroscience, 20(11), 1560-1568. doi:10.1038/nn.4641 [PubMed: 28920936]

Muirhead CS, \& Srinivasan J (2020). Small molecule signals mediate social behaviors in C. elegans. Journal of Neurogenetics, 34. doi: 10.1080/01677063.2020.1808634

Mylenko M, Boland S, Penkov S, Sampaio JL, Lombardot B, Vorkel D, ... Kurzchalia TV (2016). $\mathrm{NAD}+$ Is a food component that promotes exit from dauer diapause in Caenorhabditis elegans. PLoS One, 11(12), e0167208. doi:10.1371/journal.pone.0167208 [PubMed: 27907064]

Nathoo AN, Moeller RA, Westlund BA, \& Hart AC (2001). Identification of neuropeptide-like protein gene families in Caenorhabditis elegans and other species. Proceedings of the National Academy of Sciences of the United States of America, 98(24), 14000-14005. doi:10.1073/pnas.241231298 [PubMed: 11717458]

O’Donnell MP, Fox BW, Chao PH, Schroeder FC, \& Sengupta P (2020). A neurotransmitter produced by gut bacteria modulates host sensory behaviour. Nature, 583(7816), 415-420. doi:10.1038/ s41586-020-2395-5 [PubMed: 32555456]

Ohno Y, Shimizu S, Tokudome K, Kunisawa N, \& Sasa M (2015). New insight into the therapeutic role of the serotonergic system in Parkinson's disease. Progress in Neurobiology, 134, 104-121. doi:10.1016/j.pneurobio.2015.09.005 [PubMed: 26455457]

Oranth A, Schultheis C, Tolstenkov O, Erbguth K, Nagpal J, Hain D, ... Gottschalk A (2018). Food sensation modulates locomotion by dopamine and neuropeptide signaling in a distributed neuronal network. Neuron, 100(6), 1414-1428. e1410. doi:10.1016/j.neuron.2018.10.024 [PubMed: 30392795]

Park SK, Link CD, \& Johnson TE (2010). Life-span extension by dietary restriction is mediated by NLP-7 signaling and coelomocyte endocytosis in C. elegans. FASEB Journal: Official Publication of the Federation of American Societies for Experimental Biology, 24(2), 383-392. doi:10.1096/ fj.09-142984 [PubMed: 19783783]

Pierce SB, Costa M, Wisotzkey R, Devadhar S, Homburger SA, Buchman AR, ... Ruvkun G (2001). Regulation of DAF-2 receptor signaling by human insulin and ins-1, a member of the unusually large and diverse $C$. elegans insulin gene family. Genes \& Development, 15(6), 672-686. doi:10.1101/gad.867301 [PubMed: 11274053]

Pocock R, \& Hobert O (2010). Hypoxia activates a latent circuit for processing gustatory information in C. elegans. Nature Neuroscience 13(5), 610-614. doi: 10.1038/nn.2537 [PubMed: 20400959]

Politis M, \& Niccolini F (2015). Serotonin in Parkinson's disease. Behavioural Brain Research, 277 , 136-145. doi:10.1016/j.bbr.2014.07.037 [PubMed: 25086269] 
Prahlad V (2020). The discovery and consequences of the central role of the nervous system in the control of protein homeostasis. Journal of Neurogenetics, 34.doi: 10.1080/01677063.2020.1771333

Qin J, \& Wheeler AR (2007). Maze exploration and learning in C. elegans. Lab on a Chip, 7(2), 186192. doi:10.1039/b613414a [PubMed: 17268620]

Rankin CH (2006). Nematode behavior: The taste of success, the smell of danger!. Current Biology, 16(3), R89-R91. doi:10.1016/j.cub.2006.01.025 [PubMed: 16461270]

Reddy KC, Andersen EC, Kruglyak L, \& Kim DH (2009). A polymorphism in npr-1 is a behavioral determinant of pathogen susceptibility in C. elegans. Science, 323(5912), 382-384. doi:10.1126/ science.1166527 [PubMed: 19150845]

Rengarajan S, Yankura KA, Guillermin ML, Fung W, \& Hallem EA (2019). Feeding state sculpts a circuit for sensory valence in Caenorhabditis elegans. Proceedings of the National Academy of Sciences of the United States of America, 116(5), 1776-1781. doi:10.1073/pnas.1807454116 [PubMed: 30651312]

Riddle DL, Swanson MM, \& Albert PS (1981). Interacting genes in nematode dauer larva formation. Nature, 290(5808), 668-671. doi:10.1038/290668a0 [PubMed: 7219552]

Ringstad N (2017). Neuromodulation: The fevered mind of the worm. Current Biology, 27(8), R315R317. doi:10.1016/j.cub.2017.03.005 [PubMed: 28441568]

Rivard L, Srinivasan J, Stone A, Ochoa S, Sternberg PW, \& Loer CM (2010). A comparison of experience-dependent locomotory behaviors and biogenic amine neurons in nematode relatives of Caenorhabditis elegans. BMC Neuroscience, 11, 22. doi:10.1186/1471-2202-11-22 [PubMed: 20167133]

Roeder T (2020). The control of metabolic traits by octopamine and tyramine in invertebrates. The Journal of Experimental Biology, 223(7), jeb194282. doi:10.1242/jeb.194282 [PubMed: 32238440]

Rogers C, Reale V, Kim K, Chatwin H, Li C, Evans P, \& de Bono M (2003). Inhibition of Caenorhabditis elegans social feeding by FMRFamide-related peptide activation of NPR-1. Nat Neurosci, 6(11), 1178-1185. doi:10.1038/nn1140 [PubMed: 14555955]

Sanyal S, Wintle RF, Kindt KS, Nuttley WM, Arvan R, Fitzmaurice P, ... Van Tol HHM (2004). Dopamine modulates the plasticity of mechanosensory responses in Caenorhabditis elegans. The EMBO Journal, 23(2), 473-482. doi:10.1038/sj.emboj.7600057 [PubMed: 14739932]

Sawin ER, Ranganathan R, \& Horvitz HR (2000). C. elegans locomotory rate is modulated by the environment through a dopaminergic pathway and by experience through a serotonergic pathway. Neuron, 26(3), 619-631. doi:10.1016/S0896-6273(00)81199-X [PubMed: 10896158]

Schafer WF (2006). Genetics of egg-laying in worms. Annual Review of Genetics, 40, 487-509. doi:10.1146/annurev.genet.40.110405.090527

Sellegounder D, Yuan CH, Wibisono P, Liu Y, \& Sun J (2018). Octopaminergic signaling mediates neural regulation of innate immunity in Caenorhabditis elegans. mBio, 9(5), e01645. doi:10.1128/ mBio.01645-18

Serrano-Saiz E, Pereira L, Gendrel M, Aghayeva U, Bhattacharya A, Howell K, ... Hobert O (2017). A neurotransmitter atlas of the Caenorhabditis elegans male nervous system reveals sexually dimorphic neurotransmitter usage. Genetics, 206(3), 1251-1269. doi:10.1534/genetics.117.202127 [PubMed: 28684604]

Sharp T, \& Cowen PJ (2011). 5-HT and depression: Is the glass half-full? Current Opinion in Pharmacology, 11(1), 45-51. doi:10.1016/j.coph.2011.02.003 [PubMed: 21377932]

Srinivasan S (2020). Neuroendocrine control of lipid metabolism: Lessons from C. elegans. Journal of Neurogenetics, 34.doi: 10.1080/01677063.2020.1777116

Strumwasser F, Jacklet JW, \& Alvarez RB (1969). A seasonal rhythm in the neural extract induction of behavioral egg-laying in Aplysia. Comparative Biochemistry and Physiology, 29(1), 197-206. doi:10.1016/0010-406X(69)91735-6

Styer KL, Singh V, Macosko E, Steele SE, Bargmann CI, \& Aballay A (2008). Innate immunity in Caenorhabditis elegans is regulated by neurons expressing NPR-1/GPCR. Science, 322(5900), 460-464. doi:10.1126/science.1163673. [PubMed: 18801967] 
Sulston J, Dew M, \& Brenner S (1975). Dopaminergic neurons in the nematode Caenorhabditis elegans. Journal of Comparative Neurology, 163(2), 215-226. doi:10.1002/cne.901630207

Suo S, Culotti JG, \& Van Tol HH (2009). Dopamine counteracts octopamine signalling in a neural circuit mediating food response in C. elegans. The EMBO Journal, 28(16), 2437-2448. doi:10.1038/emboj.2009.194 [PubMed: 19609300]

Suo S, Harada K, Matsuda S, Kyo K, Wang M, Maruyama K, ... Tsuboi T (2019). Sexually dimorphic regulation of behavioral states by dopamine in Caenorhabditis elegans. Journal of Neuroscience : The Official Journal of the Society for Neuroscience, 39(24), 4668-4683. doi:10.1523/ JNEUROSCI.2985-18.2019

Taghert PH, \& Nitabach MN (2012). Peptide neuromodulation in invertebrate model systems. Neuron, 76(1), 82-97. doi:10.1016/j.neuron.2012.08.035 [PubMed: 23040808]

Takeishi A, Takagaki N, \& Kuhara A (2020). Temperature signaling underlying thermotaxis and cold tolerance in Caenorhabditis elegans. Journal of Neurogenetics, 34.doi: 10.1080/01677063.2020.1734001

Toevs LA, \& Brackenbury RW (1969). Bag cell-specific proteins and the humoral control of egg laying in Aplysia californica. Comparative Biochemistry and Physiology, 29(1), 207-216. doi:10.1016/0010-406X(69)91736-8

Wu T, Duan F, Yang W, Liu H, Caballero A, Fernandes de Abreu DA, ... Zhang Y (2019). Pheromones modulate learning by regulating the balanced signals of two insulin-like peptides. Neuron, 104(6), 1095-1109. e1095. doi:10.1016/j.neuron.2019.09.006 [PubMed: 31676170]

Yang H, Lee BY, Yim H, \& Lee J (2020). Neurogenetics of nictation, a dispersal strategy in nematodes. Journal of Neurogenetics, 34.doi: 10.1080/01677063.2020.1788552

Zang KE, Ho E, \& Ringstad N (2017). Inhibitory peptidergic modulation of C. elegans serotonin neurons is gated by T-type calcium channels. eLife, 6, e22771. doi:10.7554/eLife.22771 [PubMed: 28165324] 